\title{
Diagnostische Referate
}

Prof. Dr. Heine-Kiel: Erfahrungen und Gedanken über Tuberkulose und Tuberkulin. (Med. Klin. 1912. No. 44/45.)

Verf. bespricht in einer umfassenden Abhandlung auf Grund eigener reicher Erfahrung 1. das klinische Bild der Tuberkulose am Auge, 2. die spezifischen Reaktionen bei

Tuberkulinanwendung und ihre Bewertung. Die Mitteilung ist zunächst wohl zur Informierung der Kollegen be-stimmt, die sich nicht speziell mit Augenerkrankungen befassen. Sie ist durch 20 farbige, ganz ausgezeichnet gelungene Abbildungen von Irisveränderungen bei und nach tuberkulöser Erkrankung illustriert, die sehr lehrreich und demonstrativ sind.

Da nicht nur typische Eormen, sondern auch seltenere, aber dia-gnostisch wichtige atypische Formen und deren Folgezustände am Auge (Heterochromie, Atrophie, Katarakt, Amotio retinae) gewürdigt und in ausgewählten Krankengeschichten zum Schluß therapeutische Indikationen und Resultate besprochen werden, so sind die Erfahrungen des Verfassers für alle Fachgenossen von Wert.

Auf Einzelheiten soil hier nicht eingegangen werden.

Auf die leicht zugängliche Originalmitteilung sei aber hingewiesen.

San.-Rat. Dr. Perlía, Augenarzt, Crefeld: Ueber pyämische Embolie im Limbus corneae. (Klin. Monatsbl. f. Augenheiîk. 1912. Neue Folge. XIV. Bd. S. 741.)

Verf. beschreibt eine septische Metastase im Bandschlingennetz des Limbus - eine in dieser Form höchst seltene, jedenfalls kaum beschriebene klinische Beobachtung.

Es handelte sich um einen Kranken mit septischen Metastasen in verschiedenen Organen nach infizierter Handverletzung (Staphylo-coccus aureus).

Die Erkrankung des Auges begann unter dem Bilde einer Epi-skleritis als umscliriebene Gewebsschwellung in der Außenseite des Limbus corneae.

Später entstand hieraus eine prall gefüllte graugelbe Blase von Erbsengröße mit zähem Eiter, der aus der Tiefe zu kommen schien - bei starkem Reizzustande des ganzen Auges. Es handelte sich aber

Diagnostisch $\theta$ Referate.

205

nicht um intraokulare Metastase mit Perforation nach außen, sondern um Abszeß außerhalb des Auges auf der erwähnten Grundlage (Rand-schlingennetz). Der Abszeß reinigte sich denn axich in der Tat, voiles Sehvermögen trat wieder ein.

Kennzeichnend war, daß die Hornhaut auch in unmittelbarer iS $7 / 8$ he der Veränderung am temporalen Rande immer Mar blieb und daß Ex-sxxdat im Pupillengebiet, welches anfänglich Einblick in das Axxge ver-welirte und die Annahme einer intraokularen Eiterung nahelegte, wieder zurückging, also rein toxischer Art war.

Differentialdiagnostisch kommt eventuell in Betracht:

Variolapustel (diese ziehen aber immer die benachbarte Cornea in Mitleidenschaft, an der sie eine Einschmelzung der Randzone lierbei-führen). 
Pemphigusblasen (die aber mehr einen serösen Inhalt haben, schnellihre Epitheldecke in Fetzen abstoßen und wunde, nässende, nicht ver-tiefte Stellen hinterlassen). - Hingewiesen wird noch auf die bekannteBeobachtung, daß bei Metastasen am Auge die einzelnen Bakterieneine verschiedene Neigung zur Ansiedelung in bestiirimten Organ-gebieten haben. Sepiserreger bevorzugen die Netzhaut, Tuberkelbazillendie Aderhaut.

Hierdurch erklärt sich vielleicht axich in etwas die große Seltenheit der Beobachtung von pyämischen Metastasen im Randschlingennetz des Limbus corneae, das der Ansiedelung anscheinend keine günstigen Bedingungen bietet.

Dr. Adolf Jeß, Assistenzarzt der TJniversitäts-Augenklinik Würzburg: Angeborene hoehgradige innere Oculomotoriusschwäche. (Arch. f. Augenheilk. 1912. LXXII. Bd. S. 200.)

Paresen xxnd vollständige Lähmungen der Akkommodation und des Pupillenspie $1 / 8$ gelten im allgemeinen als bedingt durch toxische Einflüsse oder suspekt als Vorboten bzw. Begleiter allgemeiner Erkrankungen, speziell des Zentralnervensystems.

Bei Fallen zweifelhafter Aetiologie ist nach neuerdings mehr ge-würdigten Erfahrungen außerdem an Zxxsammenhang mit einer ent-zündlichen Erkrankung der Nebenhöhlen zu denken. Auch persistierende Akkommodationslähmung nach lange über-standener Diphtherie kommt zur Beobachtung.

Als kongenitale Affektion ist nahezu vollkommene Akkommodations-parese noch kaum beschrieben, wird im allgemeinen für nicht vor-kommend gehalten.

Verf.b. beschreibt einen solchen Fall bei einem 18jährigen jungenMenschen

bei dem eine innere fast völlige Oculomotoriuslähmung

d. h.Akkommodationsfähigkeit von nur 1 Dioptrie (nur Nieden 7 in $75 \mathrm{cmEntfernung)} \mathrm{und}$ abnorm weite

anscheinend reaktionslose Pupillenbestanden

und zwar wie es schien

seit der Geburt. - Wenn auch einein den ersten Lebensjahren eingetretene Bhitung

Solitärtuberkel

Encephalitis oder dergl. ätiologisch immer noch in Betracht zu ziehen ist, möchte Verf. doch an eine angeborene Aplasie im Kerngebiet in diesemFalle glauben. Junius.

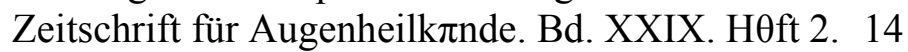

